\title{
Supercritical and Superheated Technologies: Future of Biodiesel Production
}

\section{Gaik Tin Ang ${ }^{1}$, Kok Tat Tan ${ }^{2 *}$ and Keat Teong Lee ${ }^{1}$}

${ }^{1}$ School of Chemical Engineering, University Sains Malaysia, Engineering Campus, Seri Ampangan, 4300 Nibong Tebal, Pulau Pinang, Malaysia ${ }^{2}$ Department of Petrochemical Engineering, Faculty of Engineering and Green Technology, University Tunku Abdul Rahman, Jalan University, Bandar Barat 31900 Kampar, Perak, Malaysia

Awareness on global warming has led to greater emphasis on renewable energy as the next source of energy. Renewable energy sources such as biofuels, wind energy, hydroelectric power, geothermal and solar powers are the solutions for the world not to be excessively dependent on fossil fuels. These renewable energy sources do not emit excessive harmful gases or particulates to the environmental. Instead, it has the potential to mitigate climate change and solve environmental pollution. Among these renewable energy sources, biofuels particularly biodiesel has been anticipated as the best alternative energy source in transportation sector.

Biodiesel has been receiving high attention from worldwide researchers because biodiesel is a good replacement fuels for fossil fuels. Biodiesel has low carbon emission and thus has minimal impact on environment. In addition, it also has similar chemical structure and energy content with fossil fuels. Therefore, biodiesel can be directly used in existing running vehicles without further modification. Biodiesel can be produced from a variety of feedstock, for instance edible oils, nonedible oils, animal fats and grease, which are renewable, sustainable, biodegradable and environmental friendly.

Biodiesel or fatty acid alkyl esters (FAAE) are commonly produced via trans-esterification reaction between oil (triglycerides) with alcohols. In this reversible reaction, $1 \mathrm{~mol}$ of triglycerides will react with $3 \mathrm{~mol}$ of alcohol to produce $1 \mathrm{~mol}$ of glycerol and $3 \mathrm{~mol}$ of FAAE. Fatty acid methyl ester (FAME) is produced when methanol is used as the source of alcohol, while fatty acid ethyl ester (FAEE) is produced when ethanol is used. Trans-esterification reaction can proceeds with or without the presence of catalyst. However, without any catalysts and in mild condition, the reaction proceeds in an extremely slow rate due to immiscibility between oil and alcohol.

Trans-esterification reaction can be catalyzed by both homogeneous and heterogeneous catalysts. Conventional homogeneous catalyst in commercial plant can be either acidic or alkaline such as sulfuric acid, hydrochloric acid, sodium hydroxide and potassium hydroxide. However, separation and purification of biodiesel from catalysts required complicated procedures, due to homogeneous phase of mixture. Other than that, free fatty acid (FFA) available in vegetable oils will react with catalyst to produce unwanted side product such as soap, making the feedstock in homogeneous catalyzed trans-esterification reaction required extra pre-treatment process and increase the production cost.

Subsequently, heterogeneous catalysts, for instance alkaline metal oxide, solid resins, enzyme and zeolites were developed to increase reaction rate and simultaneously simplify separation and purification of product. By using heterogeneous catalyst, FFA will not affect the yield of alkyl esters as there is no soap formation. However, it requires longer reaction time to give substantial amount of yield, implying that heterogeneous catalytic trans-esterification reaction is not efficient for commercial purpose.

In order to eliminate difficulties facing by catalytic transesterification reaction, non-catalytic trans-esterification reactions have been proposed, for instance supercritical fluid (SCF) technology and superheated methanol vapor (SMV) technology. Non-catalyzed supercritical trans-esterification reaction had been firstly proposed by Saka et al. [1] to produce biodiesel from triglycerides. In non-catalyzed supercritical technologies, alcohols (methanol, ethanol, isopropanol and isobutanol) will be heated up beyond their critical points to achieve a single fluid phases. Thus, biodiesel can be easily produced in a relatively fast rate without the presence of catalyst in SCF transesterification reaction. Separation and purification of biodiesel is relatively easier, simpler and cost effective to catalytic reactions. Table 1 shows the critical temperature and pressure for selected components that are commonly employed in SCF reaction.

At ambient conditions, triglycerides and free fatty acid are relatively non-polar compounds which will not soluble in alcohol. SCF application in trans-esterification reaction is the mixture of alcohol and triglycerides that are heated and pressurized above its critical temperature and critical pressure. Beyond its critical point, alcohol possesses increased mass diffusivity, decreased viscosity and a density that can be manipulated over a large range through relatively small changes in temperature and pressure. For instance, it is clearly shown in Figure 1 [2] that soybean oil and oleic acid are fully miscible with methanol at $300^{\circ} \mathrm{C}$ and $1650 \mathrm{psia}$, thus allowing the reaction to proceed even without the presence of catalysts.

Other than that, phase equilibrium between methanol and triglycerides during biodiesel production was studied by Glišić and Skala [3] from subcritical to supercritical region. It was reported that methanol and triglycerides are in equilibrium liquid phase from ambient conditions to subcritical condition. In addition, phase distribution will be affected by reaction mixture, temperature and pressure as shown in Figure 2. At supercritical stage $\left(270^{\circ} \mathrm{C}\right.$ and 200 bars), there is only a single phase exist during the methanolysis reaction that could produce $95 \%$ conversion of triglycerides.

The first advantage of SCF for biodiesel production is its simplicity in product separation as there is no catalyst and unwanted side product formed. Next, various types of oil feedstock can be directly trans-esterified by SCF despite the presence of free fatty acid and water content [4]. The reaction rate in SCF is relatively higher than conventional catalytic trans-esterification which need longer hours

*Corresponding author: Kok Tat Tan, Department of Petrochemical Engineering, Faculty of Engineering and Green Technology, University Tunku Abdul Rahman, Jalan University, Bandar Barat 31900 Kampar, Perak, Malaysia, Tel: +60 5468 8888; Fax: +60 5466 7449; E-mail: tankt@utar.edu.my

Received June 13, 2015; Accepted June 15, 2015; Published June 20, 2015

Citation: Ang GT, Tan KT, Lee KT (2015) Supercritical and Superheated Technologies: Future of Biodiesel Production. J Adv Chem Eng 5: e106. doi:10.4172/2090-4568.1000e106

Copyright: ( 2015 Ang GT et al. This is an open-access article distributed under the terms of the Creative Commons Attribution License, which permits unrestricted use, distribution, and reproduction in any medium, provided the original author and source are credited. 


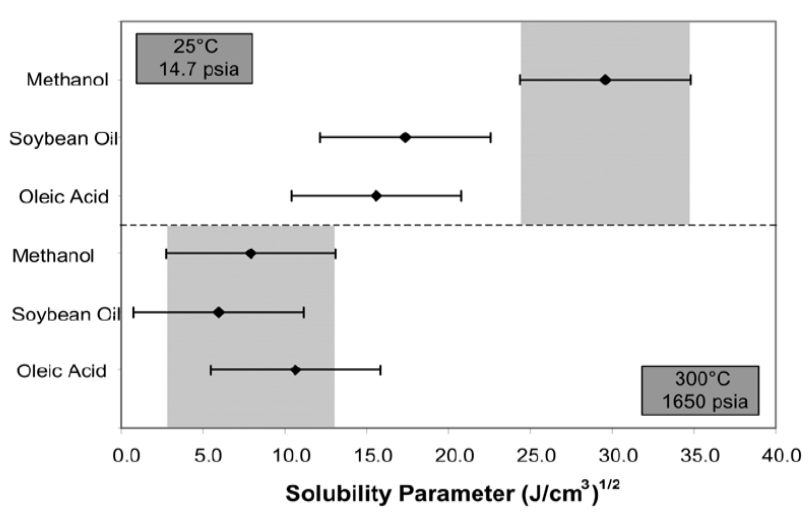

Figure 1: Hansen solubility parameters for methanol, soybean oil and oleic acid at different miscibility range [2].

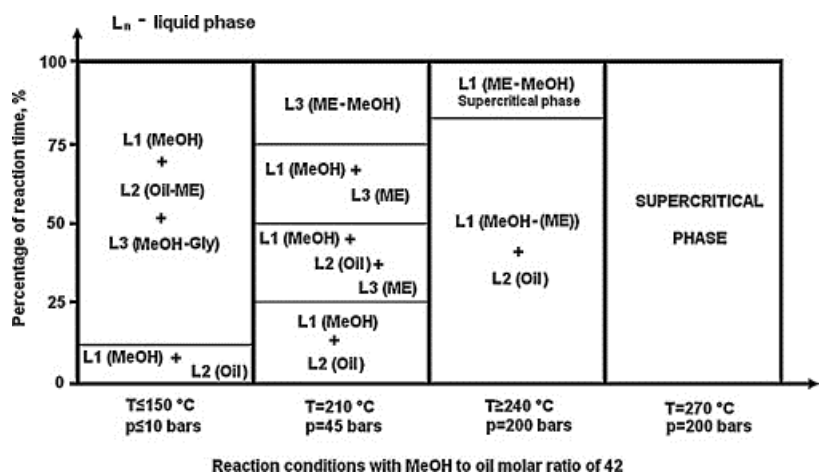

Figure 2: Phase transition during methanolysis of triglycerides at different reaction conditions [3].

of reaction time. However, SCF requires a high energy to reach supercritical stage, making it economically unattractive.

Therefore, a new emerging technology, known as superheated methanol vapor (SMV) was initially proposed by Yamazaki et al. [5]. Superheated methanol refers to methanol vapor that is above the boiling point of methanol $\left(65^{\circ} \mathrm{C}\right)$. It possesses a lot of energy to react with triglycerides for biodiesel production. Moreover, superheated methanol could produce high quality light-colored biodiesel or commonly known as "water-white" biodiesel.

In SMV technology, the reaction is also known as reactive distillation process biodiesel and glycerol. Subsequently, the products will be distillated by superheated vapor from the liquid phase into vapor phase. Reaction temperature in SMV technique is relatively high at the range of $220-290^{\circ} \mathrm{C}$ and atmospheric pressure (0.1 MPa) [5]. As the operating temperature does not exceed the boiling point of all the components, both FAME and glycerol can be easily obtained in the gas sample product. Table 2 shows the boiling point for different triglycerides, methyl esters, methanol and glycerol at different vapor pressure [6].

Although methanol is employed excessively compared with supercritical or conventional technology, methanol could be recycled easily as there is no unwanted soap or by-product. Methanol vapor could be easily separated from biodiesel by using fractional distillation column since both biodiesel and glycerol have higher boiling points than methanol will condense into liquid phase, leaving behind a pure methanol vapor.
One of the main advantages of SMV is simple product separation and purification. In addition, cost of catalyst, pre-treatment on feedstock, post-treatment of product could be avoided. SMV technology also has high tolerance towards feedstock with high water and free fatty content such as Jatropha curcas [7] and waste cooking oil [8]. Other than that, economic analysis on SMV technology conducted by Nabetani et al. [8], had shown that SMV required lower production cost than conventional alkaline catalyst. A designed productivity of $6000 \mathrm{~kL} / \mathrm{yr}$ was used to estimate the production cost needed. The cost required was estimated to be 40.2 yen/L in SMV comparing with 62.5 yen/L in alkaline catalyst method [8]. Thus, it is clearly shown that superheated methanol vapor method could reduce the cost involved in biodiesel production.

As a conclusion, SCF and SMV technologies could be the future in biodiesel production due to simplicity of product separation and purification. The enormous advantages of these processes should be taken into consideration by biodiesel producers throughout the world.

\begin{tabular}{|c|c|c|}
\hline Solvent & Critical temperature $\left.\mathbf{~}^{\circ} \mathbf{C}\right)$ & Critical pressure $\mathbf{( M P a )}$ \\
\hline Methanol & 239 & 8.09 \\
\hline Ethanol & 243 & 6.38 \\
\hline Isopropanol & 236 & 5.37 \\
\hline Isobutanol & 275 & 4.30 \\
\hline $\begin{array}{c}\text { Carbon } \\
\text { dioxide }\end{array}$ & 31 & 7.39 \\
\hline $\begin{array}{c}\text { Methyl } \\
\text { acetate }\end{array}$ & 234 & 4.69 \\
\hline $\begin{array}{c}\text { Dimethyl } \\
\text { carbonate }\end{array}$ & 275 & 4.63 \\
\hline
\end{tabular}

Table 1: Critical properties for several reactants in SCF technology.

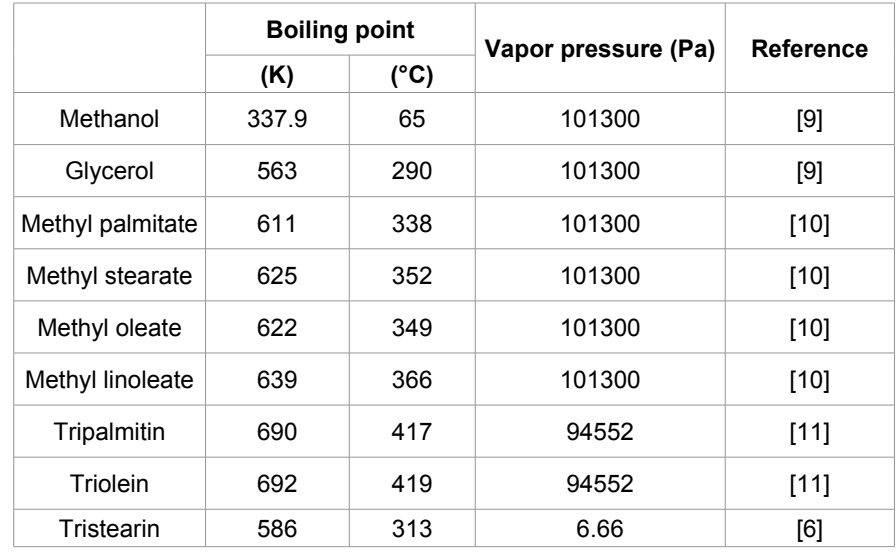

Table 2: The boiling point of components.

\section{References}

1. Saka S, Kusdiana D (2001) Biodiesel fuel from rapeseed oil as prepared in supercritical methanol. Fuel 80: 225-231.

2. Hansen CM (2007) Hansen solubility parameters: a user's handbook. USA CRC press.

3. Glisic SB, Skala DU (2010) Phase transition at subcritical and supercritical conditions of triglycerides methanolysis. J Supercrit Fluids 54: 71-80.

4. Ang GT, Ooi SN, Tan KT, Lee KT, Mohamed AR (2015) Optimization and kinetic studies of sea mango (Cerbera odollam) oil for biodiesel production via supercritical reaction. Energy Convers Manag 99: 242-251.

5. Yamazaki R, Iwamoto S, Nabetani H, Osakada K, Miyawaki O, et al. (2007) Noncatalytic alcoholysis of oils for biodiesel fuel production by a semi-batch process. Japan Journal of Food Engineering 8: 11-19. 
Citation: Ang GT, Tan KT, Lee KT (2015) Supercritical and Superheated Technologies: Future of Biodiesel Production. J Adv Chem Eng 5: e106. doi:10.4172/2090-4568.1000e106

Page 3 of 3

6. Maeda H, Hagiwara S, Nabetani H, Sagara Y, Soerawidjaya TH, et al. (2008) Biodiesel fuels from palm oil via the non-catalytic transesterification in a bubble column reactor at atmospheric pressure: A kinetic study. Renewable Energy 33: $1629-1636$.

7. Ang GT, Tan KT, Lee KT, Mohamed AR (2014) Biodiesel production via injection of superheated methanol technology at atmospheric pressure. Energy Convers Manag 87: 1231-1238

8. Nabetani H, Hagiwara S, Suzuki Y, Araki T, Sagara Y, et al. (2009) Economical efficiency of a non-catalytic alcoholysis process for production of biodiesel fuel. MRS online Proceedings, Cambridge Univ Press, UK.
9. Perry RH, Green D, Maloney J (1997) Perry's handbook of chemical engineering

10. Yuan W, Hansen AC, Zhang Q (2005) Vapor pressure and normal boiling point predictions for pure methyl esters and biodiesel fuels. Fuel 84: 943-950.

11. Santander CMG, Rueda SMG, de Lima da Silva N, de Camargo CL, Kieckbusch TG, et al. (2012) Measurements of normal boiling points of fatty acid ethyl esters and triacylglycerols by thermogravimetric analysis. Fuel 92: 158-161. 